\title{
ArcheoSciences
}

Revue d'archéométrie

33 (suppl.) | 2009

Mémoire du sol, espace des hommes

\section{Geophysical contributions to the understanding of Northern Great Plains archaeology, USA}

\section{Kenneth Kvamme}

\section{(2) OpenEdition}

1 Journals

\section{Electronic version}

URL: https://journals.openedition.org/archeosciences/1358

DOI: 10.4000/archeosciences.1358

ISBN: 978-2-7535-1599-4

ISSN: 2104-3728

Publisher

Presses universitaires de Rennes

\section{Printed version}

Date of publication: 30 October 2009

Number of pages: $97-99$

ISBN: 978-2-7535-0943-6

ISSN: $1960-1360$

\section{Electronic reference}

Kenneth Kvamme, "Geophysical contributions to the understanding of Northern Great Plains archaeology, USA", ArcheoSciences [Online], 33 (suppl.) | 2009, Online since 30 October 2011, connection on 01 February 2022. URL: http://journals.openedition.org/archeosciences/1358 ; DOI: https://doi.org/10.4000/archeosciences.1358 


\title{
Geophysical contributions to the understanding of Northern Great Plains archaeology, USA
}

\author{
Kenneth Kvamme*
}

Key words: Northern Great Plains USA, Village archaeology, Multi-dimensional geophysical surveys, Anthropological interpretation.

Geophysical surveys over the past dozen years have contributed significant new knowledge to the understanding of prehistoric and historic village sites in the Northern Great Plains, in what is now North and South Dakota, USA. These surveys have covered entire villages, or significant parts of villages, utilizing magnetic gradiometry, electrical resistance, electromagnetic induction, ground-penetrating radar (GPR), and thermal infrared methods. The village sites, which date between AD 1200-1860, were composed of earthlodges, square, rectangular, oval, or dome-shaped houses (depending on the time period and culture) built of a frame of wood and covered with a quarter-meter of soil. A half-dozen to over a hundred earthlodges formed a village, which was typically fortified with a deep ditch and palisade owing to incessant warfare. Prior to the advent of extensive geophysical surveys in the late 1990s, much was known about these villages from ethnography, historical documents, and traditional archaeology. Indeed, diaries and eye-witness accounts abound from the nineteenth century and artists like Karl Bodmer and George Catlin left behind a visual record. Moreover, a plethora of archaeological work has documented material culture and house form changes into the distant past. The surfaces of many of the village sites leave a great deal of readily-interpretable information as well. The slow pace of soil formation in the Northern Plains means that depressions in the surface yet remain over the loci of houses and fortification ditches, permitting the ready mapping of village layout and internal structure.
Despite this wealth of knowledge, geophysical surveys have contributed numerous new insights into Northern Plains village archaeology. Earthlodge locations are revealed by increased magnetism and resistance around their perimeters, largely resulting from eroded roof sediments. Compacted floors often generate strong radar reflections. These surveys generate data that permit the identification of earthlodge size and form, their orientation (different cultures or time periods saw house entryways facing different directions), and their number within a village, all much more reliably than surface depression data which is often vague, absent, or less complete. Numbers of houses yield important estimates of population size for carrying capacity or other demographic studies. Some cultures and periods exhibit a more-or-less random distribution of houses within a village, while others show within-village clusters or even systematic arrangements in linear rows, which geophysical survey data greatly clarify. In some villages magnetic gradiometry surveys indicate a large number of burned houses, testifying to warfare and even the sacking of a village.

That these villages were fortified is well-known from ethnography, eye-witness accounts, historic paintings, and the presence of fortification ditches visible in the surface. What we learn from the historical record or the landscape today generally reflects the terminal occupation period of each village when settlement form may have been much different from earlier times. Many geophysical surveys indicate that pioneer settlements were much larger than these other lines

* Department of Anthropology, Old Main 330, University of Arkansas, Fayetteville, AR 72701 USA. (kkvamme@uark.edu) 


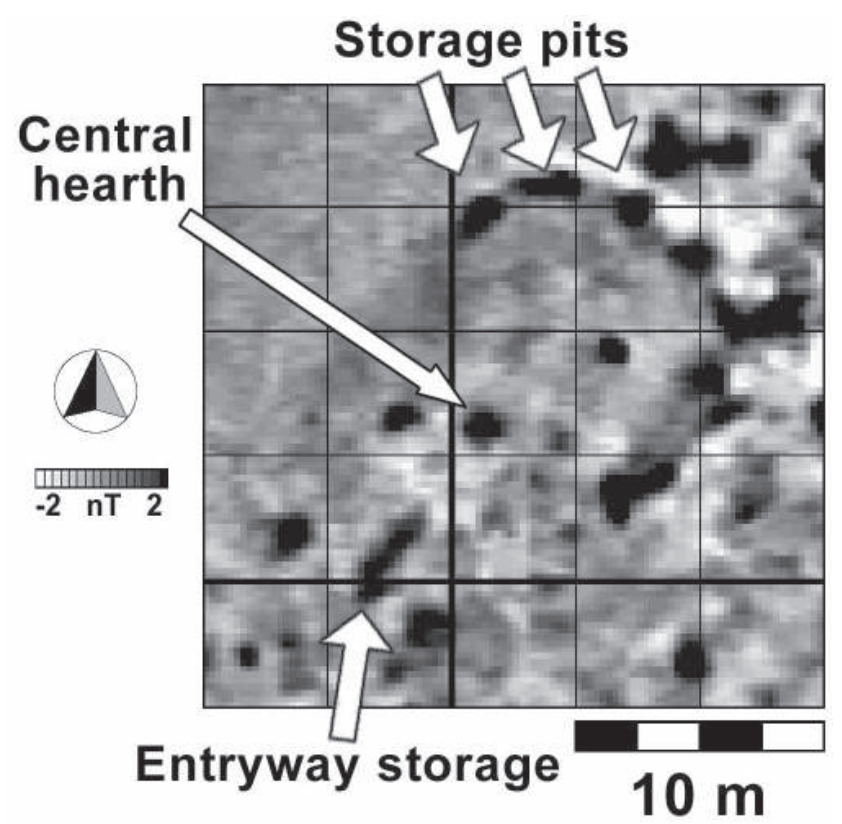

Figure 1: Magnetic gradiometry evidence from Huff Village showing corn storage pits surrounding a house with a centrally placed hearth.

of evidence indicate. At the Double Ditch State Historic Site in North Dakota, named for its two fortification ditches visible in the surface, geophysical surveys identified two additional fortification ditches far from the village core, which more than doubled the suspected size of the settlement. Similar findings at other sites point to much larger populations than previously expected. These villages contracted beginning in the sixteenth century as waves of smallpox and constant warfare reduced populations, forcing smaller villages that required new defensive rings around their reduced perimeters. In addition to locating these buried and hidden ditches, the geophysical surveys contribute much to knowledge of defensive characteristics, such as bastion spacing and form.

Geophysical surveys also reveal details about the village exterior, such as the loci of trails emanating from them, and many internal characteristics that were not previously known or well-understood. Traditional archaeological work focused primarily on the excavation of houses to reveal their form and something about living conditions. Most houses contain interior corn storage pits which were bell-shaped in crosssection, about 1.5-2 m deep, and used to store maize for later consumption. Yet, magnetic gradiometry surveys reveal that for every internal storage pit approximately 5-10 times more storage pits were placed exterior to houses. Two strong spatial patterns emerge: a ring of storage pits surrounding each house plus a line of storage pits along the interior side of the palisade,

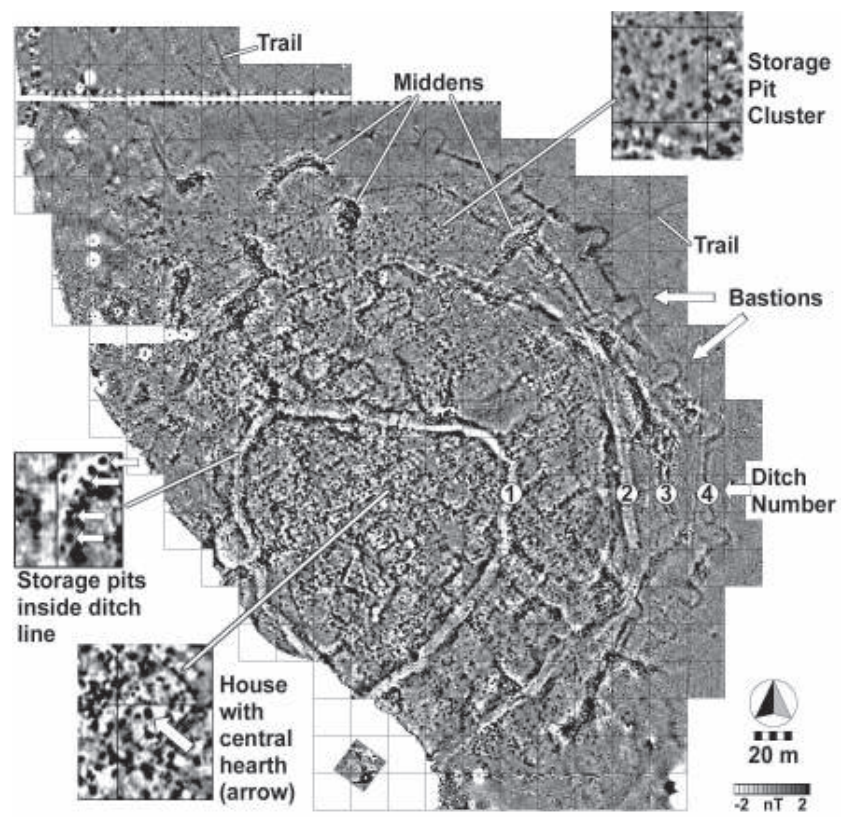

Figure 2: Magnetic gradiometry evidence from the Double Ditch State Historic Site showing four fortification ditches with bastions, exit trails, numerous houses, middens, and corn storage pits.

in addition to randomly distributed clusters. The vast number of corn storage pits now revealed gives further evidence of large populations and long, intensive occupations.

Geophysical data reveal other settlement characteristics. Each earthlodge had a centrally-placed hearth while rectangular houses possessed several hearths along their centerlines, wellknown archaeologically but also clearly visible in the magnetic evidence. In historic occupations iron artifacts generate readily detected anomalies that suggest differential access to European or Euroamerican trade goods, with some earthlodges exhibiting far more iron goods than others. Earthlodge villages are also well-known for extensive middens that resulted from their long and intense occupations. Filled with sediments from hearth-cleanings, fire-cracked rock, broken ceramics, bone and organic matter, they tend to be highly magnetic and electrically resistant. Moreover, in addition to large middens, the geophysical data reveal numerous small middens local to and affiliated with individual houses or house groups. GPR surveys also reveal something about midden structure. Radar reflections reveal earlier midden surfaces and individual dumping episodes that show they were built laterally, growing outward from a core rather than upward. The absence of anomalies within a village is informative too. The Mandan, one of the principal tribes of the region, uniformly created central plazas for ceremonial and other purposes, which are easily recognized by a complete absence of geophysical anomalies. 
Figure 3: GPR evidence from the Double Ditch State Historic Site: a) depth slices through a house from $10 \mathrm{~cm}-80 \mathrm{~cm}$ below surface showing perimeter walls, central hearth and interior storage pits (arrows), b) profile though a midden showing sloping stratigraphy, c) profile from historic 1906 excavations showing sloping stratigraphy.
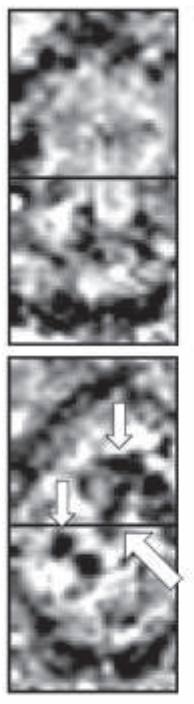

a
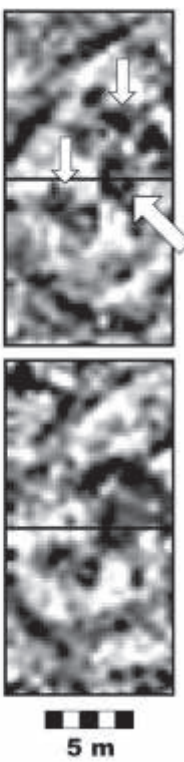

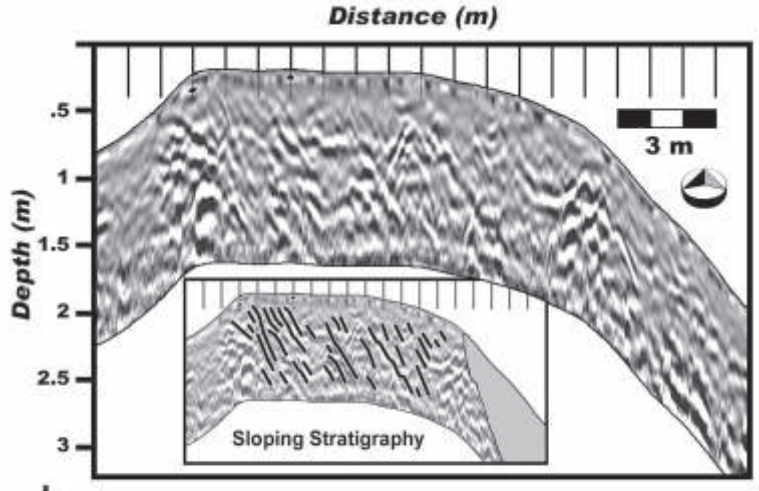

b

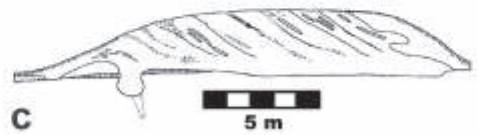

\section{REFERENCES}

Kvamme, K. L., 2008. Archaeological prospecting at the Double Ditch State Historic Site, North Dakota, USA. Archaeological Prospection, 15: 62-79.

Kvamme, K. L., 2007. Geophysical mappings and findings in Northern Plains village sites. In Ahler, S. A., Kay, M., (dir.). Plains Village Archaeology: Bison Hunting Farmers in the Central and Northern Plains, University of Utah Press, Salt Lake City, 210-221.

Kvamme, K. L., 2003. Multidimensional prospecting in North American Great Plains village sites. Archaeological Prospection, 10: 131-142. 